\title{
Usefulness of the Japanese version of the 5-D itch scale for rating pruritus experienced by patients undergoing hemodialysis
}

Naoko Takahashi ${ }^{1 *}$, Taku Yoshizawa', Aiko Okubo ${ }^{1}$, Junko Kumagai ${ }^{1}$, Hideki Kawanishi ${ }^{2}$, Shinichiro Tsuchiya ${ }^{2}$, Misaki Moriishi ${ }^{3}$, Takao Masaki ${ }^{4}$ and Toshiya Ebata ${ }^{5}$

\begin{abstract}
Background: Pruritus in patients undergoing hemodialysis reduces quality of life via insomnia and depression, and negatively affects prognosis. For diagnosing pruritus, selecting therapeutic strategies, and determining therapeutic outcomes, methods are needed for objectively quantifying the degree of itchiness. In 2015, the Japanese version of the 5-D itch scale (5D-J), originally developed in the USA in 2010, was developed as a simple self-administered questionnaire; it evaluated the degree of itchiness based on five components: (1) duration of itchiness, (2) degree of itchiness, (3) direction of itchiness, (4) disability caused by itchiness, and (5) distribution of itchiness. 5D-J is useful for comprehensively assessing multiple elements related to itchiness. We used 5D-J to assess the degree of itchiness experienced by patients undergoing hemodialysis to investigate its clinical usefulness.
\end{abstract}

Methods: Subjects were 336 patients undergoing maintenance hemodialysis at our facility in October 2016; they were selected from 383 patients, of whom 20 were excluded because their itchiness had a dermatologic origin and 27 were excluded because their localized itchiness was related to vascular access, respectively. The status of itchiness (duration, degree, direction, disability, and distribution) of the patients was surveyed in October 2016 using 5D-J; total scores were calculated and used for assessing the itchiness experienced by patients. We additionally investigated whether 5D-J scores correlated with visual analog scale (VAS) and Shiratori severity scores for pruritus.

Results: Degree was reported as "not present" by 124 patients (36.9\%), "mild" by 164 (48.8\%), "moderate" by $46(13.7 \%)$, "severe" by $2(0.6 \%)$, and "unbearable" by $0(0 \%)$. Total score was 5 points in 55 patients (16.4\%), 6-9 in 176 (52.4\%), 10-14 in 95 (28.3\%), 15-19 in 9 (2.7\%), 20-24 in $1(0.3 \%)$, and 25 in 0 (0\%). The 5D-J total and VAS scores were strongly correlated $(r=0.7159 ; p<0.001)$. The 5D-J total score correlated with "daytime itchiness" $(r=0.6441 ; p<0.001)$ and "nighttime itchiness" $(r=0.6352 ; p<0.001)$ on the Shiratori severity score.

Conclusions: 5D-J may be useful for objectively assessing itchiness experienced by patients undergoing hemodialysis.

Keywords: Japanese 5-D itch scale, 5-D itch scale, Visual analog scale, Shiratori severity score, Hemodialysis, Pruritus, Quality of life

\footnotetext{
* Correspondence: u-23naoko@hi3.enjoy.ne.jp

1'Akane-Foundation Omachi Tsuchiya Clinic, 2-8-35 Omachi Higashi, Asa

Minami-ku, Hiroshima 731-0124, Japan

Full list of author information is available at the end of the article
}

(c) The Author(s). 2018 Open Access This article is distributed under the terms of the Creative Commons Attribution 4.0 International License (http://creativecommons.org/licenses/by/4.0/), which permits unrestricted use, distribution, and reproduction in any medium, provided you give appropriate credit to the original author(s) and the source, provide a link to the Creative Commons license, and indicate if changes were made. The Creative Commons Public Domain Dedication waiver (http://creativecommons.org/publicdomain/zero/1.0/) applies to the data made available in this article, unless otherwise stated. 


\section{Background}

Approximately $60-80 \%$ of patients undergoing hemodialysis have pruritus, and many cases are refractory to treatment [1-8]. Moreover, degree of itchiness and sleep disorders are strongly correlated. Sleep disorders were previously identified in patients with moderate or worse itchiness at a rate of 1.9- to 3.7-fold higher than in patients without itchiness [5]. In addition, patients reporting moderate or severe itchiness that affects daily life also have depression at a rate of 1.3- to 1.7-fold higher than patients reporting no itchiness [2]. The degree of itchiness and survival rate are negatively correlated in patients undergoing hemodialysis [2, 3]. Thus, because pruritus in patients undergoing hemodialysis reduces quality of life (QOL) owing to sleep disorders, depression, and other adverse effects and negatively impacts prognosis, it is a major complication that requires careful treatment.

When diagnosing pruritus, selecting therapeutic strategies, and predicting therapeutic outcomes, both the patient's individual and subjective sense of the degree of itchiness needs to be assessed numerically based on the use of a uniform scale and quantitatively based on an objective measure. The scales used for assessing itchiness include the visual analog scale (VAS) [9-12], numerical rating scale (NRS) [10-12], and verbal rating scale (VRS) [10-12]. VAS and the Shiratori severity score for pruritus (Shiratori score) [13], divided into a type of VRS, and the Kawashima classification [14], a simplified version of the Shiratori score, are commonly used in Japan. However, because VAS rates itchiness in increments along a $100-\mathrm{mm}$ line and NRS uses integers from 0 to 10 to indicate the degree of itchiness, problems such as "the degree of itchiness is difficult to accurately express because the standard is vague," "it is impossible to assess multiple aspects of itchiness with a single number," and "the score is influenced by the symptoms of itchiness and the patient's emotional state immediately before taking the test" have been reported $[11,15]$. VRS, in which patients express the degree of itchiness by selecting words, has received the following criticism: "There are too few categories with which the patient is required to express minute changes in itchiness, and the differences between the categories are unclear, which results in quantitative inaccuracy" [12].

By contrast, the Japanese version of the 5-D itch scale (5D-J), developed by Ebata et al. in 2015 [16], is based on the 5-D itch scale that was originally developed in the USA in 2010 [17] and uses a point system to assess the duration, degree, direction, and distribution of itchiness as well as the disability caused by itchiness. Each component is rated on a scale of $1-5$, giving a maximum score of 25 . The $5 \mathrm{D}-\mathrm{J}$ is a self-administered questionnaire that the patient can complete quickly and easily, with a scoring system that allows for quantification. While the VAS and the Shiratori score evaluate only the degree of pruritus, the 5D-J evaluates pruritus multidimensionally by assessing duration, direction, effect on QOL, and distribution of itchiness, in addition to degree of itchiness. This detailed assessment of pruritus is an advantage of the $5 \mathrm{D}-\mathrm{J}$ that may make it useful in routine clinical practice and enables an overall evaluation of multiple factors associated with pruritus [17]. In Japan, a validation study in adult atopic dermatitis patients has already confirmed the reliability, validity, and responsiveness of the 5D-J [18].

In this study, we used 5D-J to assess the degree of itchiness experienced by patients undergoing hemodialysis and assessed its clinical usefulness.

\section{Methods}

Subjects were 336 patients undergoing maintenance hemodialysis at our facility in October 2016. The patients were selected from 383 patients, of whom 20 were excluded because their itchiness was identified as being dermatologic in origin and an additional 27 were excluded because their localized itchiness was related to vascular access. Table 1 summarizes the baseline characteristics of the patients. There were 213 men and 123 women; median age was 70 years, median number of months on dialysis was 66 months, and primary illnesses were diabetes $(n=152)$, chronic glomerulonephritis $(n=87)$, nephrosclerosis $(n=35)$, other $(n=35)$, and unknown $(n=27)$.

The itchiness of all patients was assessed in terms of five components (duration, degree, direction, disability, and distribution) using 5D-J in October 2016 (Fig. 1). Responses were used to calculate total scores, which were then used to indicate the status of itchiness among patients undergoing hemodialysis at our facility. We also investigated the possibility of a correlation between 5D-J and itchiness determined using VAS and Shiratori scores, which the patients completed at the same time as $5 \mathrm{D}-\mathrm{J}$.

VAS is designed as a horizontal line with markings that range from "no itchiness" $(0 \mathrm{~mm})$ on the extreme left to "worst possible (or "unbearable") itchiness" $(100 \mathrm{~mm})$ on the extreme right. In cases of "worst possible itchiness," patients further indicated the degree of itchiness on a vertical line. The distance (in $\mathrm{mm}$ ) from the extreme left side to the marking on the vertical line was determined.

The Shiratori score separately indicates itchiness during daytime and nighttime. Daytime itchiness is rated on the following 5-point scale: 0, no itchiness (no symptoms); 1 , bearable without scratching (negligible); 2 , subsides with some scratching (slight); 3, subsides with 
Table 1 Patient baseline characteristics and comparison between groups with 5D-J score $\geq 9$ and $\leq 8$

\begin{tabular}{|c|c|c|c|c|}
\hline & \multirow{2}{*}{$\begin{array}{l}\text { Total }(n=336) \\
\text { Number }(\%)\end{array}$} & \multicolumn{2}{|l|}{ 5D-J total scores } & \multirow[b]{2}{*}{$p$ value } \\
\hline & & $\geq 9(n=145)$ number $(\%)$ & $\leq 8(n=191)$ number $(\%)$ & \\
\hline Male/female & $213(63.4) / 123(36.6)$ & $93(64.1) / 52(35.9)$ & $120(62.8) / 71(37.2)$ & $0.801^{*}$ \\
\hline Median, IQR age (years) & $70,63-77$ & $71,61-78$ & $69,62-77$ & $0.226^{* *}$ \\
\hline Median, IQR duration of hemodialysis (months) & $66,33-131$ & $67,38-119$ & $64,27-151$ & $0.889^{* *}$ \\
\hline \multicolumn{5}{|l|}{ Primary illness of chronic kidney disease } \\
\hline Diabetes mellitus & $152(45.2)$ & $74(51.0)$ & $78(40.8)$ & $0.063^{*}$ \\
\hline Chronic glomerulonephritis & $87(25.9)$ & $33(22.8)$ & $54(28.3)$ & $0.253^{*}$ \\
\hline Nephrosclerosis & $35(10.4)$ & $14(9.7)$ & $21(11.0)$ & $0.691^{*}$ \\
\hline Other & $35(10.4)$ & $12(8.3)$ & $23(12.0)$ & $0.263^{*}$ \\
\hline Unknown & $27(8.0)$ & $12(8.3)$ & $15(7.9)$ & $0.888^{*}$ \\
\hline \multicolumn{5}{|l|}{ Comorbidities } \\
\hline Hypertension & $312(92.9)$ & $134(92.4)$ & $178(93.2)$ & $0.783^{*}$ \\
\hline Ischemic heart disease & $79(23.5)$ & $45(31.0)$ & $34(17.8)$ & $<0.005^{*}$ \\
\hline Congestive heart failure & $64(19.1)$ & $26(17.9)$ & $38(19.9)$ & $0.650^{*}$ \\
\hline Cerebral vascular disease & $85(25.3)$ & $41(28.3)$ & $44(23.0)$ & $0.274^{*}$ \\
\hline Peripheral arterial disease & $39(11.6)$ & $19(13.1)$ & $20(10.5)$ & $0.456^{*}$ \\
\hline Chronic lung disease & $24(7.1)$ & $12(8.3)$ & $12(6.3)$ & $0.482^{*}$ \\
\hline Chronic liver disease & $19(5.7)$ & $11(7.6)$ & $8(4.2)$ & $0.182^{*}$ \\
\hline Malignant neoplasm & $19(5.7)$ & $9(6.2)$ & $10(5.2)$ & $0.703^{*}$ \\
\hline \multicolumn{5}{|l|}{ Medication for pruritus } \\
\hline Moisturizers & $142(42.3)$ & $79(54.5)$ & $63(33.0)$ & $<0.001^{*}$ \\
\hline Topical steroids & $83(24.7)$ & $54(15.2)$ & $29(10.0)$ & $<0.001^{*}$ \\
\hline Other topical drugs & $35(10.4)$ & $22(15.2)$ & $13(6.8)$ & $<0.001^{*}$ \\
\hline Oral antihistamines & $13(3.9)$ & $8(5.5)$ & $5(2.6)$ & $0.172^{*}$ \\
\hline Anti-allergy injections & $2(0.6)$ & $2(1.4)$ & $0(0.0)$ & $0.186^{* * *}$ \\
\hline Nalfurafine & 39 (11.6) & $19(13.1)$ & $20(10.5)$ & $0.456^{*}$ \\
\hline \multicolumn{5}{|l|}{ Laboratory parameters (median, IQR) } \\
\hline Serum albumin (g/dL) & $3.6,3.4-3.8$ & $3.5,3.3-3.7$ & $3.6,3.4-3.8$ & $0.070^{* *}$ \\
\hline Serum corrected calcium (mg/dL) & $8.4,8.1-8.8$ & $8.9,8.4-9.2$ & $8.8,8.4-9.1$ & $0.974^{* *}$ \\
\hline Phosphorus (mg/dL) & $4.9,4.1-5.4$ & $4.9,4.1-5.4$ & $4.9,4.1-5.4$ & $0.823^{* * * *}$ \\
\hline Whole PTH (pg/mL) & $76.4,51.7-116.2$ & $79.2,56.7-124.7$ & $71.9,47.2-109.7$ & $0.101^{* *}$ \\
\hline Hemoglobin (g/dL) & $11.3,10.7-11.9$ & $11.2,10.7-11.8$ & $11.4,10.7-11.9$ & $0.283^{* *}$ \\
\hline ß2-microglobulin (mg/L) & $22.9,20.0-26.4$ & $23.1,20.4-27.0$ & $22.8,19.6-25.9$ & $0.174^{* *}$ \\
\hline $\mathrm{Kt} / \mathrm{N}$ & $1.5,1.4-1.6$ & $1.5,1.4-1.6$ & $1.5,1.4-1.6$ & $0.801^{* *}$ \\
\hline
\end{tabular}

Data are presented as $n(\%)$, unless stated otherwise. $p$ values were calculated using $x^{2}$ test ${ }^{*}$, Mann-Whitney $U$ test $^{* * *}$, Fisher's exact test ${ }^{* * *}$, and Student's $t$ test ${ }^{* * * *}$, respectively

considerable scratching (moderate); and 4, does not subside with scratching and leads to more scratching (severe). Nighttime itchiness is rated on the following 5 -point scale: 0 , no itchiness (no symptoms); 1 , very little itchiness noticed when in bed, not particularly aware of itchiness, and able to sleep (negligible); 2, some itchiness that subsides when scratched, not waking up because of itchiness (slight); 3, waking up because of itchiness, can sleep after scratching but unconscious scratching while asleep (moderate); and 4, almost completely unable to sleep because of itchiness, frequent scratching but itchiness only worsens (severe).

We investigated the correlation between 5D-J, VAS, and Shiratori (daytime and nighttime) scores using Spearman's rank correlation coefficient. The results were determined as follows: $r=0$, no correlation; $0<|r| \leq 0.2$, almost no correlation; $0.2<|r| \leq 0.4$, weak correlation; $0.4<|r| \leq 0.7$, moderate correlation; $0.7<|r|<1.0$, strong correlation; and $r=1.0$ or -1.0 , perfect correlation. We used the $\chi^{2}$, Mann-Whitney $U$, Fisher's exact, and 


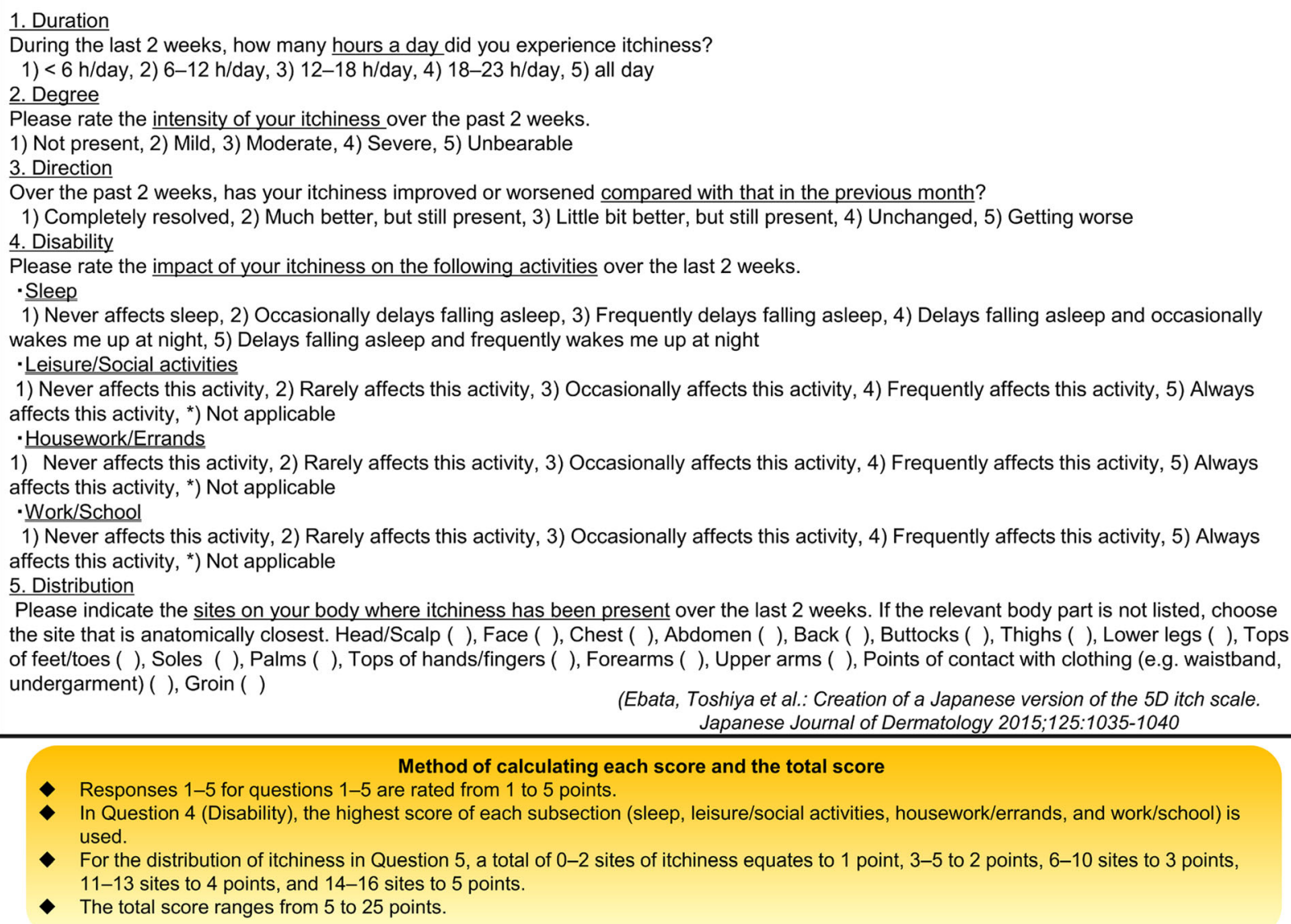

(Ebata, Toshiya et al.: Creation of a Japanese version of the $5 D$ itch scale. Japanese Journal of Dermatology 2015;125:1035-1040

Responses 1-5 for questions 1-5 are rated from 1 to 5 points.

- In Question 4 (Disability), the highest score of each subsection (sleep, leisure/social activities, housework/errands, and work/school) is used.

- For the distribution of itchiness in Question 5, a total of 0-2 sites of itchiness equates to 1 point, 3-5 to 2 points, $6-10$ sites to 3 points, $11-13$ sites to 4 points, and $14-16$ sites to 5 points.

- The total score ranges from 5 to 25 points.

Fig. 1 Japanese version of the 5-D itch scale

Student's $t$ tests for the other analyses. In all analyses, $p$ values less than 0.05 were considered statistically significant. All statistical analyses were performed with SPSS version 23.0 (IBM Japan, Ltd., Tokyo, Japan).

This study was conducted with the approval of the Tsuchiya General Hospital Institutional Review Board for Human Investigation (approval number: E170619-2) and performed according to the principles of the Declaration of Helsinki. Prior verbal consent was obtained from all patients enrolled in this study. The fact that patients provided consent was recorded in their medical records. The need for written informed consent was waived due to the strict maintenance of patients' anonymity and the observational nature of the study.

\section{Results}

\section{Assessment of itchiness using 5D-J Duration}

In total, 307 patients (91.4\%) reported "less than $6 \mathrm{~h}$," 17 (5.1\%) reported "6-12 h," 8 (2.4\%) reported " $12-$ $18 \mathrm{~h}$, " 1 (0.3\%) reported "18-23 h," and $3(0.9 \%)$ reported "all day."

\section{Degree}

Overall, 124 patients (36.9\%) reported "not present," 164 (48.8\%) reported "mild," 46 (13.7\%) reported "moderate," 2 (0.6\%) reported "severe," and 0 (0\%) reported "unbearable."

In addition, we divided the patients into two groups, those who reported pruritus as "not present" (124 patients) and those who reported at least "mild" (212 patients) pruritus. Comparison of baseline characteristics and laboratory parameters between the two groups revealed that patients with "at least mild" pruritus had a significantly higher rate of chronic liver disease $(p<0.05)$ and significantly more use of moisturizers, topical steroids, and other topical drugs for pruritus treatment $(p<0.001$ for each) (Table 2). As for laboratory parameters, patients with "at least mild" pruritus had significantly higher whole PTH levels $(p<0.05)$ (Table 2).

\section{Direction}

Among all patients, 62 (18.5\%) reported "completely resolved," 71 (21.1\%) reported "much better, but still present," 61 (18.2\%) reported "a little bit better, but still 
Table 2 Comparison of baseline characteristics between the "not present" and "at least mild" groups

\begin{tabular}{|c|c|c|c|}
\hline & $\begin{array}{l}\text { Not present }(n=124) \\
\text { number }(\%)\end{array}$ & $\begin{array}{l}\text { Mild or above }(n=212) \\
\text { number }(\%)\end{array}$ & $p$ value \\
\hline Male/female & $74(59.7) / 50(40.3)$ & $139(65.6) / 73(34.4)$ & $0.280^{*}$ \\
\hline Median, IQR age (years) & $69,62-76$ & $71,63-78$ & $0.275^{* *}$ \\
\hline Median, IQR duration of hemodialysis (months) & $72,30-152$ & $63,34-123$ & $0.301^{* *}$ \\
\hline \multicolumn{4}{|l|}{ Primary illness of chronic kidney disease } \\
\hline Diabetes mellitus & $50(40.3)$ & $102(48.1)$ & $0.166^{*}$ \\
\hline Chronic glomerulonephritis & 38 (30.6) & $49(23.1)$ & $0.128^{*}$ \\
\hline Nephrosclerosis & $12(9.7)$ & $23(10.8)$ & $0.734^{*}$ \\
\hline Other & $15(12.1)$ & $20(9.4)$ & $0.441^{*}$ \\
\hline Unknown & $9(7.3)$ & $18(8.5)$ & $0.688^{*}$ \\
\hline \multicolumn{4}{|l|}{ Comorbidities } \\
\hline Hypertension & $114(91.9)$ & $198(93.4)$ & $0.616^{*}$ \\
\hline Ischemic heart disease & $24(19.4)$ & $55(25.9)$ & $0.169^{*}$ \\
\hline Congestive heart failure & $27(21.8)$ & $37(17.5)$ & $0.330^{*}$ \\
\hline Cerebral vascular disease & $28(22.6)$ & $57(26.9)$ & $0.381^{*}$ \\
\hline Peripheral arterial disease & $15(12.1)$ & $24(11.3)$ & $0.830^{*}$ \\
\hline Chronic lung disease & $8(6.5)$ & $16(7.5)$ & $0.707^{*}$ \\
\hline Chronic liver disease & $3(2.4)$ & $16(7.5)$ & $<0.05^{*}$ \\
\hline Malignant neoplasm & $6(4.8)$ & $13(6.1)$ & $0.620^{*}$ \\
\hline \multicolumn{4}{|l|}{ Medication for pruritus } \\
\hline Moisturizers & $27(21.8)$ & $115(54.2)$ & $<0.001^{*}$ \\
\hline Topical steroids & $5(4.0)$ & $78(36.8)$ & $<0.001^{*}$ \\
\hline Other topical drugs & $3(2.4)$ & $32(15.1)$ & $<0.001^{*}$ \\
\hline Oral antihistamines & $2(1.6)$ & $11(5.2)$ & $0.143^{* * *}$ \\
\hline Anti-allergy injections & $0(0.0)$ & $2(0.9)$ & $0.533^{* * *}$ \\
\hline Nalfurafine & $10(8.1)$ & $29(13.7)$ & $0.121^{*}$ \\
\hline \multicolumn{4}{|l|}{ Laboratory parameters (median, IQR) } \\
\hline Serum albumin (g/dL) & $3.7,3.5-3.8$ & $3.6,3.4-3.8$ & $0.164^{* *}$ \\
\hline Serum corrected calcium (mg/dL) & $8.8,8.5-9.2$ & $8.8,8.4-9.2$ & $0.949^{* *}$ \\
\hline Phosphorus (mg/dL) & $4.9,4.2-5.4$ & $4.8,3.9-5.5$ & $0.937^{* * * *}$ \\
\hline Whole PTH (pg/mL) & $63.6,47.4-101.4$ & $81.8,55.0-124.9$ & $<0.05^{* *}$ \\
\hline Hemoglobin (g/dL) & $11.4,10.7-12.0$ & $11.3,10.8-11.9$ & $0.557^{* *}$ \\
\hline ß2-microglobulin (mg/L) & $22.9,19.9-25.9$ & $23.0,20.1-26.5$ & $0.571^{* *}$ \\
\hline $\mathrm{Kt} / \mathrm{N}$ & $1.5,1.4-1.6$ & $1.5,1.4-1.6$ & $0.760^{* * * * *}$ \\
\hline
\end{tabular}

Data are presented as $n(\%)$, unless stated otherwise. $p$ values were calculated using $x^{2}$ test ${ }^{*}$, Mann-Whitney $U$ test $^{* *}$, Fisher's exact test ${ }^{* * *}$, Student's $t$ test ${ }^{* * * *}$, and Welch's test ${ }^{* * * * *}$, respectively

present," 139 (41.4\%) reported "unchanged," and 3 (0.9\%) reported "getting worse."

\section{Disability}

Sleep "Never affects sleep" was reported by 239 patients (71.1\%), “occasionally delays falling asleep" by 73 (21.7\%), "frequently delays falling asleep" by $9(2.7 \%)$, "delays falling asleep and occasionally wakes me up at night" by 10 (3.0\%), and "delays falling asleep and frequently wakes me up at night" by 5 (1.5\%).

Leisure/social activities "Never affects leisure/social activities" was reported by 268 patients $(79.8 \%)$, "rarely affects leisure/social activities" by 23 (6.8\%), "occasionally affects leisure/social activities" by $23(6.8 \%)$, "frequently affects leisure/social activities" by $3(0.9 \%)$, "always affects leisure/social activities" by $2(0.6 \%)$, and "not applicable" by 17 (5.1\%). 
Housework/errands "Never affects housework/errands" was reported by 273 patients (81.3\%), "rarely affects housework/errands" by 25 (7.4\%), "occasionally affects housework/errands" by 17 (5.1\%), "frequently affects housework/errands" by 1 (0.3\%), "always affects housework/errands" by $2(0.6 \%)$, and "not applicable" by 18 (5.4\%).

Work/school Among all patients, "never affects work/ school" was reported by 256 patients (76.2\%), "rarely affects work/school" by 25 (7.4\%), "occasionally affects work/school" by 10 (3.0\%), "frequently affects work/ school" by 3 (0.9\%), "always affects work/school" by 2 $(0.6 \%)$, and "not applicable" by $40(11.9 \%)$.

\section{Distribution}

Almost half of the patients $(n=150 ; 44.6 \%)$ reported "back," followed by "head/scalp" ( $n=82 ; 24.4 \%)$, "abdomen" $(n=62 ; 18.5 \%)$, and "lower legs" $(n=54 ; 16.1 \%)$ (Fig. 2).

\section{Total scores}

Total score was 5 points in 55 patients (16.4\%), 6-9 points in 176 patients (52.4\%), 10-14 points in 95 patients (28.3\%), $15-19$ points in 9 patients (2.7\%), $20-24$ points in 1 patient $(0.3 \%)$, and 25 points in 0 (0\%).

The median total score of all patients was 8 points. We divided the patients into two groups based on their total score, with 145 patients in the " $\geq 9$ points" group and 191 patients in the " $\leq 8$ points" group. Comparison of baseline characteristics and laboratory parameters of the two groups revealed that the " $\geq 9$ points" group included significantly more patients with ischemic heart disease $(p<0.005)$ and significantly more patients who had been prescribed moisturizers, topical steroids, and other topical drugs for the treatment of pruritus $(p<0.001$ for each medication; Table 1$)$.

\section{Correlation between 5D-J and VAS}

A strong correlation was observed between degree on 5D-J and VAS score $(r=0.7588 ; p<0.001)$. Correlations were also found between both disability $(r=0.6005 ; p<0.001)$ and distribution and the VAS score $(r=0.4945 ; p<0.001$; Table 3). The 5D-J total scores and VAS scores were also strongly correlated ( $r=0.7159 ; p<0.001$; Fig. 3 ).

\section{Correlation between 5D-J and Shiratori score Daytime}

A strong correlation was observed between degree on 5D-J and the Shiratori score $(r=0.7457 ; p<0.001)$. Correlations were also found between both disability $(r=0.5201 ; p<0.001)$ and distribution and the Shiratori score $(r=0.4674 ; p<0.001$; Table 4$)$. In addition, a correlation was observed between the 5D-J total score and Shiratori score $(r=0.6441 ; p<0.001$; Fig. 4$)$.

\section{Nighttime}

Correlations were found between degree, disability, and distribution on 5D-J and the Shiratori score $(r=0.6099$, $r=0.5811$, and $r=0.4097$, respectively; $p<0.001$; Table 5). A correlation was also observed between the 5D-J total score and Shiratori score $(r=0.6352 ; p<0.001$; Fig. 5).

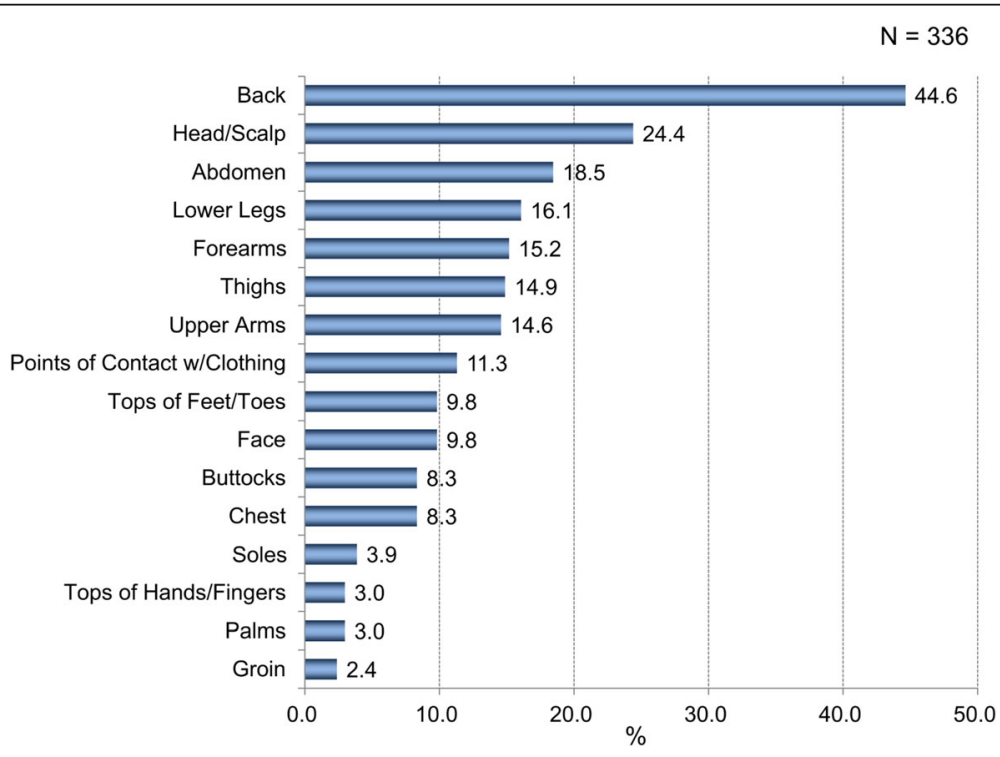

Fig. 2 Distribution of itchiness 
Table 3 Correlation between 5D-J and VAS

\begin{tabular}{llc}
\hline & \multicolumn{2}{l}{ Spearman's rank correlation coefficient } \\
\cline { 2 - 3 }$r$ & $p$ value \\
\hline Duration & 0.3845 & $<0.001$ \\
Degree & 0.7588 & $<0.001$ \\
Direction & 0.2330 & $<0.001$ \\
Disability & 0.6005 & $<0.001$ \\
Distribution & 0.4945 & $<0.001$ \\
Total & 0.7159 & $<0.001$ \\
\hline
\end{tabular}

\section{Correlation between 5D-J and objective parameters}

We examined the relationship between 5D-J score and objective parameters, and no correlation was found (Table 6).

\section{Discussion}

In this study, we assessed the status of pruritus among patients undergoing hemodialysis at our facility using $5 \mathrm{D}-\mathrm{J}$, which is a new assessment scale for itchiness. We also investigated the usefulness of $5 \mathrm{D}-\mathrm{J}$ by determining whether correlations existed between 5D-J and VAS and Shiratori scores, which the patients completed at the same time as 5D-J.

In summary, our assessment of the status of itchiness using 5D-J provided the following results. For duration, $91.4 \%$ of the patients reported $<6 \mathrm{~h} /$ day. For degree, $63.1 \%$ reported mild or more severe itchiness, which is comparable to the $60-80 \%$ previously reported [1-8]. However, $14.3 \%$ of the patients in our study reported moderate or more severe itchiness, which was lower than the $30-50 \%$ previously reported [1-8]. In addition, no patients reported unbearable itchiness. For disability, the percentages of patients who reported "never affects

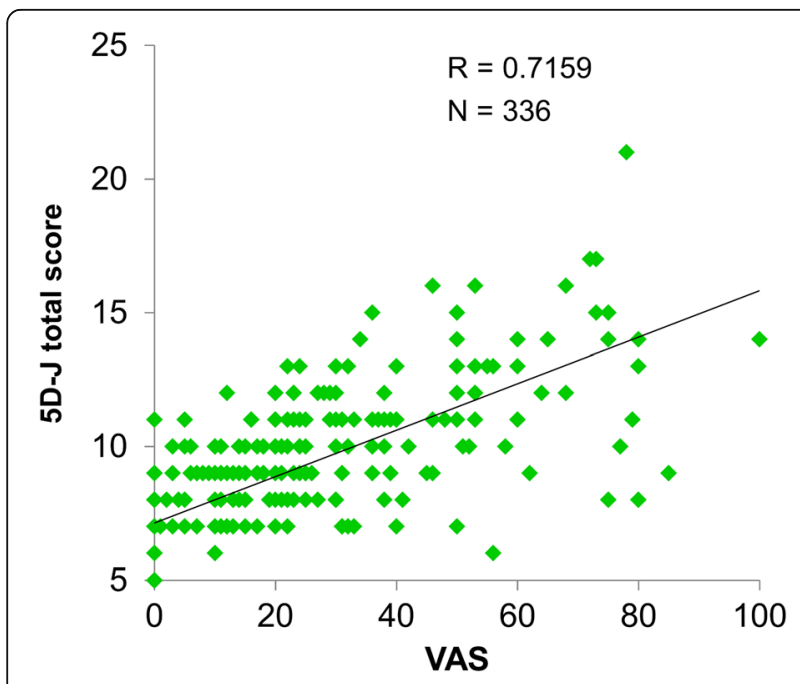

Fig. 3 Correlation between the 5D-J total score and VAS score
Table 4 Correlation between 5D-J and the Shiratori score (daytime)

\begin{tabular}{lll}
\hline & \multicolumn{2}{l}{ Spearman's rank correlation coefficient } \\
\cline { 2 - 3 }$r$ & $p$ value \\
\hline Duration & 0.2251 & $<0.001$ \\
Degree & 0.7457 & $<0.001$ \\
Direction & 0.2309 & $<0.005$ \\
Disability & 0.5201 & $<0.001$ \\
Distribution & 0.4674 & $<0.001$ \\
Total & 0.6441 & $<0.001$ \\
\hline
\end{tabular}

(this activity)" were as follows: sleep, $71.1 \%$; leisure/social activities, 79.8\%; housework/errands, 81.3\%; and work/school, $76.2 \%$. These results indicate that itchiness did not negatively affect the QOL of 70 to $80 \%$ of the patients at our facility. An assessment of the total scores indicated that $>95 \%$ scored $\leq 14$ points (of a possible maximum 25 points). In the high-scoring group, comprising patients with total scores $>8$, the number of patients with comorbid ischemic heart disease was significantly higher; the reason for this is unclear. Moreover, in the high-scoring group, significantly more patients were prescribed moisturizers, topical steroids, and other topical drugs. We believe the reason for this difference is that, compared with the low scoring group, factors that worsen pruritus such as dry skin, inflammation due to scratching, and secondary rashes may have been more prevalent in the high-scoring group.

In the group with "at least mild" pruritus, whole PTH level was significantly higher, as was the rate of chronic liver disease. Secondary hyperparathyroidism [3, 5] and viral hepatitis [19] have been reported to cause pruritus

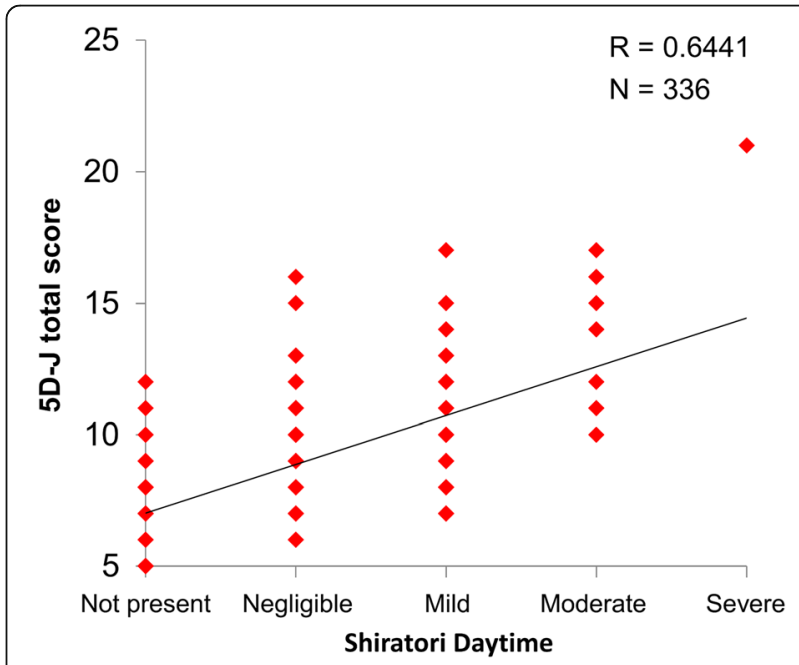

Fig. 4 Correlation between the 5D-J total score and the Shiratori score (daytime) 
Table 5 Correlation between the 5D-J total score and Shiratori score (nighttime)

\begin{tabular}{lll}
\hline & \multicolumn{2}{l}{ Spearman's rank correlation coefficient } \\
\cline { 2 - 3 }$r$ & $p$ value \\
\hline Duration & 0.3000 & $<0.001$ \\
Degree & 0.6099 & $<0.001$ \\
Direction & 0.2265 & $<0.001$ \\
Disability & 0.5811 & $<0.001$ \\
Distribution & 0.4097 & $<0.001$ \\
Total & 0.6352 & $<0.001$ \\
\hline
\end{tabular}

in hemodialysis patients. Thus, we believe clinicians should take particular note of pruritus in hemodialysis patients with secondary hyperparathyroidism or viral hepatitis.

The therapeutic strategy for pruritus experienced by patients undergoing hemodialysis was revised at our facility in June 2009 by creating and introducing a new treatment algorithm. In particular, in addition to investigating dialysis techniques (e.g., protein adsorptive dialysis with a polymethylmethacrylate membrane and predilution online hemodiafiltration), as well as pharmacotherapies including the selective $\mathrm{\kappa}$-opioid receptor agonist nalfurafine hydrochloride, we actively promoted skin care using moisturizers and provided lifestyle guidance. This treatment algorithm has been reported to be useful $[20,21]$. In the current study, we found that in general, the duration of itchiness was short, degree was mild or less severe, and few patients experienced a negative effect on QOL owing to moderate or more severe itchiness or disability. We believe that these results

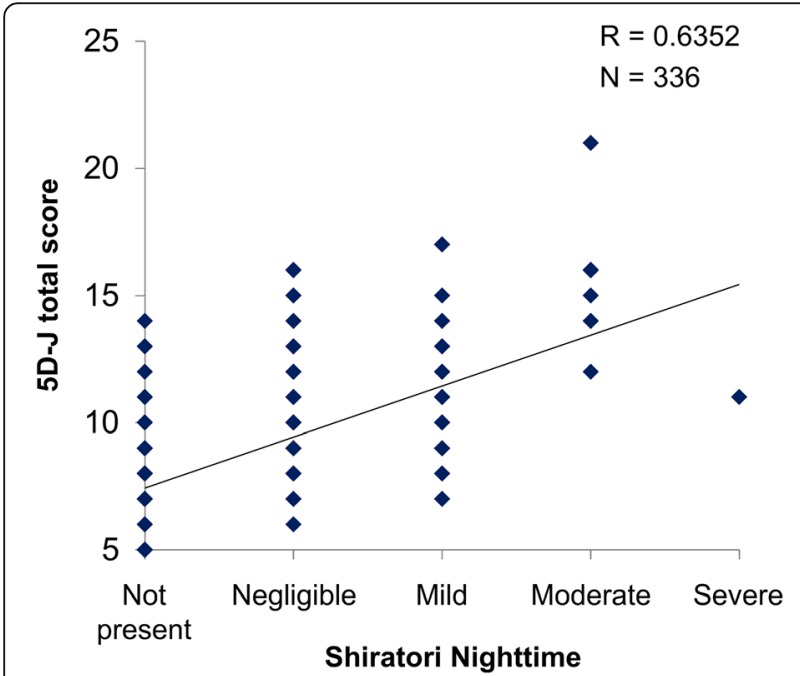

Fig. 5 Correlation between the 5D-J total score and the Shiratori score (nighttime)
Table 6 Correlation between 5D-J total score and objective parameters

\begin{tabular}{lll}
\hline & \multicolumn{2}{l}{ Spearman's rank correlation coefficient } \\
\cline { 2 - 3 } & $r$ & $p$ value \\
\hline Albumin $(\mathrm{g} / \mathrm{dL})$ & -0.140 & $<0.05$ \\
Corrected calcium $(\mathrm{mg} / \mathrm{dL})$ & 0.067 & 0.222 \\
Phosphorus $(\mathrm{mg} / \mathrm{dL})$ & 0.022 & 0.690 \\
Whole PTH $(\mathrm{pg} / \mathrm{mL})$ & 0.096 & 0.083 \\
Hemoglobin $(\mathrm{g} / \mathrm{dL})$ & -0.042 & 0.442 \\
B2-microglobulin $(\mathrm{mg} / \mathrm{L})$ & 0.043 & 0.448 \\
Kt $/ \mathrm{N}$ & -0.026 & 0.648 \\
\hline
\end{tabular}

reflect the success of the treatment algorithm currently being used at our facility.

Our study of itchiness distribution indicated that almost half of the patients reported "back," which is consistent with previous findings [1, 4]; after this body location, patients reported the head/scalp, abdomen, and lower legs. The distribution section comprises 16 detailed sites on the body where itchiness can be experienced. Because this allows patients to indicate the precise sites of itchiness, such data would be useful in appropriately selecting sites that require treatment.

Our study of the correlation between 5D-J, VAS, and Shiratori scores indicated that degree, disability, and distribution were all correlated, in some cases moderately or strongly. Our analysis of direction showed that 139 patients (41.4\%) reported "unchanged." However, we believe that this reflects the fact that no change occurred in the symptoms experienced by patients who originally reported "no itchiness" or "mild itchiness." Furthermore, the correlation coefficients between these sections, VAS scores, and Shiratori scores were $r=0.2330, r=0.2309$, and $r=0.2265$, respectively, indicating weak correlation. Thus, these results may not allow for an objective assessment of itchiness.

A strong correlation was observed between 5D-J total scores and VAS scores, as well as a correlation between 5D-J total scores and both daytime and nighttime Shiratori scores. In their study of 409 patients undergoing hemodialysis, Lai et al. reported a strong correlation between the 5-D itch scale and NRS $(r=0.831 ; p<0.001)$ and also reported that the 5 -D itch scale was a reliable multidimensional assessment scale of itchiness for use in patients undergoing hemodialysis [22]. In the present study, a strong or moderate correlation was found between multiple components, as well as 5D-J total scores, VAS scores, and Shiratori scores, possibly indicating that $5 \mathrm{D}-\mathrm{J}$ is useful for comprehensively assessing itchiness experienced by patients undergoing hemodialysis.

Limitations of this study should be considered. As a result of continued treatment of pruritus based on 
our treatment algorithm, the number of patients with "severe" pruritus has gradually decreased over the years. At the time of our study in October 2016, of the 336 study patients, only $2(0.6 \%)$ had "severe" itchiness and none had "unbearable" itchiness. The scarcity of patients with "severe" or "unbearable" pruritus may have influenced our study results and may have limited the assessment of this scoring system. In addition, because we did not compare 5D-J with other scales such as NRS or VRS to identify whether correlations exist between these scales, we are unable to comment further on the reliability of 5D-J.

\section{Conclusions}

The 5D-J is a simple, yet comprehensive, assessment system for pruritus that evaluates not only the degree but also the overall status of pruritus based on multiple features. Thus, it may be more useful than the VAS and the Shiratori score as an objective assessment scale of pruritus in hemodialysis patients.

\section{Abbreviations}

5D-J: Japanese version of the 5-D itch scale; NRS: Numerical rating scale; QOL: Quality of life; VAS: Visual analog scale; VRS: Verbal rating scale

\section{Acknowledgements}

The authors are grateful to all the medical staff who participated in this study.

\section{Availability of data and materials}

The datasets used and/or analyzed during the current study are available from the corresponding author on reasonable request.

\section{Authors' contributions}

NT conceived the study and wrote the first draft of this manuscript. TY contributed to the study design, coordinated the study, and conducted the statistical analysis. AO, JK, HK, ST, MM, and TM contributed to the study design and were involved in the production of the first draft of parts of this manuscript. TE developed the Japanese version of the 5-D itch scale and contributed to the study design and drafting parts of this manuscript. All authors read and approved the final manuscript.

\section{Ethics approval and consent to participate}

This study was conducted with the approval of the Institutional Review Board of Tsuchiya General Hospital (no. E170619-2). Prior verbal consent was obtained from all patients enrolled in this study. The fact that patients provided consent was recorded in their medical records.

\section{Consent for publication}

Not applicable.

\section{Competing interests}

The authors declare that they have no competing interests.

\section{Publisher's Note}

Springer Nature remains neutral with regard to jurisdictional claims in published maps and institutional affiliations.

\section{Author details}

'Akane-Foundation Omachi Tsuchiya Clinic, 2-8-35 Omachi Higashi, Asa Minami-ku, Hiroshima 731-0124, Japan. ${ }^{2}$ Department of Artificial Organs, Akane-Foundation, Tsuchiya General Hospital, Hiroshima, Japan

${ }^{3}$ Akane-Foundation Nakajima Tsuchiya Clinic, Hiroshima, Japan. ${ }^{4}$ Department of Nephrology, Hiroshima University Hospital, Hiroshima, Japan. ${ }^{5}$ Chitofuna Dermatology Clinic, Tokyo, Japan.

Received: 11 December 2017 Accepted: 13 June 2018

Published online: 11 July 2018

\section{References}

1. Omori K, Aoike I, Aoyagi $H$, Aoyagi R, Imai K, Iwafuchi $Y$, et al. Risk factors for uremic pruritus in long-term hemodialysis patients. J Jpn Soc Dial Ther. 2001;34:1469-77. (in Japanese)

2. Pisoni RL, Wikström B, Elder SJ, Akizawa T, Asano Y, Keen ML, et al. Pruritus in haemodialysis patients: international results from the Dialysis Outcomes and Practice Patterns Study (DOPPS). Nephrol Transplant. 2006;21:3495-505.

3. Narita I, Alchi B, Omori K, Sato F, Ajiro J, Saga D, et al. Etiology and prognostic significance of severe uremic pruritus in chronic hemodialysis patients. Kidney Int. 2006;69:1626-32.

4. Yamada S, Sakurai H, Kasuga H, Kawahara H. Investigation of the status of uremic pruritus in hemodialysis patients and the efficacy of nalfurafine hydrochloride-questionnaire administered to 1,936 patients from 17 clinics in Tokai area of Japan. J Jpn Soc Dial Ther. 2012:45:1133-40. (in Japanese)

5. Kimata N, Fuller DS, Saito A, Akizawa T, Fukuhara S, Pisoni RL, et al. Pruritus in hemodialysis patients: results from the Japanese Dialysis Outcomes and Practice Patterns Study (JDOPPS). Hemodial Int. 2014;18:657-67.

6. Remakrishnan K, Bond TC, Claxton A, Sood VC, Kootsikas M, Agnese W, et al. Clinical characteristics and outcomes of end-stage renal disease patients with self-reported pruritus symptoms. Int J Nephrol Renovasc Dis. 2014; 7:1-12.

7. Mathur VS, Lindberg J, Germain M, Block G, Tumlin J, Smith M, et al. ITCH National Registry Investigators: a longitudinal study of uremic pruritus in hemodialysis patients. Clin J Am Soc Nephrol. 2010;5:1410-9.

8. Shirazian S, Aina O, Park Y, Chowdhury N, Leger K, Hou L, et al. Chronic kidney disease-associated pruritus: impact on quality of life and current management challenges. Int J Nephrol Renovasc Dis. 2017:10:11-26.

9. Furue M, Ebata T, Ikoma A, Takeuchi S, Kataoka Y, Takamori K, et al. Verbalizing extremes of the visual analogue scale for pruritus: a consensus statement. Acta Derm Venereol. 2013;93:214-21.

10. Williamson A, Hoggart B. Pain: a review of three commonly used pain rating scales. J Clin Nurs. 2005;14:798-804.

11. Reich A, Heisig M, Phan NQ, Taneda K, Takamori K, Takeuchi S, et al. Visual analogue scale: evaluation of the instrument for the assessment of pruritus. Acta Derm Venereol. 2012;92:497-501.

12. Phan NQ, Blome C, Fritz F, Gerss J, Reich A, Ebata T, et al. Assessment of pruritus intensity: prospective study on validity and reliability of the visual analogue scale, numerical rating scale and verbal rating scale in 471 patients with chronic pruritus. Acta Derm Venereol. 2012;92:502-7.

13. Shiratori A. Therapeutic outcomes of the use of mequitazine (LM-209) in severe dermatological diseases. Nishinihon J Dermatol. 1983;45:470-3. (in Japanese)

14. Kawashima $M$, Tango $T$, Noguchi $T$, Inagi M, Nakagawa $H$, Harada S Addition of fexofenadine to a topical corticosteroid reduces the pruritus associated with atopic dermatitis in a 1-week randomized, multicentre, double-blind, placebo-controlled, parallel-group study. Br J Dermatol. 2003; 148:1212-21.

15. Ständer $\mathrm{S}$, Augustin $\mathrm{M}$, Reich $\mathrm{A}$, Blome $\mathrm{C}$, Ebata T, Phan NQ, et al. Pruritus assessment in clinical trials: consensus recommendations from the International Forum for the Study of Itch (IFSI) Special Interest Group Scoring Itch in Clinical Trials. Acta Derm Venereol. 2013;93:509-14.

16. Ebata T, Ishiuji Y, Saeki H, Nakagawa H. Creation of a Japanese version of the 5D itch scale. Jpn J Dermatol. 2015:125:1035-40. (in Japanese)

17. Elman S, Hynan LS, Gabriel V, Mayo MJ. The 5-D itch scale: a new measure of pruritus. Br J Dermatol. 2010;162:587-93.

18. Ebata T. Recent advances in the evaluation of itch and introduction of the Japanese version of the 5D-itch scale in adult patients with atopic dermatitis; Atopic Dermatitis Treatment Study Group. Skin Res. 2015;14:S1-6. (in Japanese)

19. Chiu YL, Chen HY, Chuang YF, Hsu SP, Lai CF, Pai MF, et al. Association of uraemic pruritus with inflammation and hepatitis infection in haemodialysis patients. Nephrol Dial Transplant. 2008:23:3685-9.

20. Takahashi N, Yoshizawa T, Kumagai J. Efficacy and safety of long-term (104week) administration of nalfurafine hydrochloride. J Jpn Soc Dial Ther. 2013; 46:371-8. (in Japanese) 
21. Takahashi N, Yoshizawa T, Kumagai J, Kawanishi H, Moriishi M, Masaki T, et al. Response of patients with hemodialysis-associated pruritus to new treatment protocol with nalfurafine hydrochloride: a retrospective surveybased study. Ren Replac Ther. 2016;2:27.

22. Lai JW, Chen HC, Chou CY, Yen HR, Li TC, Sun MF, et al. Transformation of 5-D itch scale and numerical rating scale in chronic hemodialysis patients. BMC Nephrol. 2017;18:56

Ready to submit your research? Choose BMC and benefit from:

- fast, convenient online submission

- thorough peer review by experienced researchers in your field

- rapid publication on acceptance

- support for research data, including large and complex data types

- gold Open Access which fosters wider collaboration and increased citations

- maximum visibility for your research: over $100 \mathrm{M}$ website views per year 